Advances in Materials Science and Engineering: An International Journal (MSEJ), Vol. 3, No. 2, June 2016

\title{
THERMAL AND METROLOGICAL STUDIES ON YTTRIA STABILIZED ZIRCONIA THERMAL BARRIER COATINGS AND A SIMULATED MODEL TO CO-RELATE THE FINDINGS
}

\author{
Shankar. V ${ }^{1}$, V.R. Reghu ${ }^{2}$, Parvati Ramaswamy ${ }^{3}$ and KevinVattappara ${ }^{4}$ \\ ${ }^{1}$ Professor \& Principal Investigator, ${ }^{2}$ Associate Professor and PhD Scholar, \\ ${ }^{3}$ Professor, and ${ }^{4}$ Research Fellow \\ Surface Engineering Laboratory \\ Department of Mechanical Engineering, Faculty of Engineering, Christ University \\ Bangalore-560074, India \\ shankar.vechristuniversity.in
}

\begin{abstract}
Thermal Barrier Coatings (TBCs), routinely prepared from Ceramic based compositions (typically $8 \% \mathrm{Y}_{2} \mathrm{O}_{3}-\mathrm{ZrO}_{2}$ or $\left.8 Y S Z\right)$ are being engineered to protect the metallic components from degradation in applications like gas turbines, jet and automotive engines. With a goal of finding improved TBC materials a wide variety of ceramics are being researched worldwide. Before physically preparing the TBCs of uncommon compositions in the laboratory, their suitability to perform can be predicted. Limited accessibility to detailed and realistic information on the influence of newer compositions (other than 8YSZ) on TBCs warrants methods to obtain this information.

In this paper, 8YSZ TBCs coated onto aluminium substratesare studied for thermal fatigue, thermal barrier and materials characteristics to determine the reliability of the coating configuration to withstand the harshness of test conditions under the framework of experiments. Thereafter, the results have been used to corroboratethe developed simulation model. Results obtained via thermal tests confirm the suitability of the model and we can predict the thermal barrier effects of TBCs when prepared from materials other than YSZ.
\end{abstract}

\section{KEYWORDS}

$\mathrm{Y}_{2} \mathrm{O}_{3}$-stabilized Zirconia plasma sprayed TBCs, Structural phase analysis, TBC metrology, simulation model of TBCs on aluminium substrate.

\section{BACKGROUND INFORMATION}

At the Mechanical Engineering Department, Faculty of Engineering Christ University, Bangalore, one of the major research focuses is on diesel engine. Based on the submission of a research proposal [1] and under the Major Research Project (MRP) scheme, an in-house funded project has been sanctioned [2] during November 2013 by the Centre of Research Projects, Christ University for a period of three years. The aim and objective in three phases is to a) create a stateof-the-art facility catering to various class of diesel engines in the range of five to hundred HP where in (i) five to ten HP single cylinder engines are used for irrigation and tiller applications and (ii) sixty to eighty HP class four cylinder engines are used for light motor vehicle 
applications, b) evaluate the base line engine characteristics by extensive testing and endurance testing and c) work on engine modification by going in for Low Heat Rejection (LHR) engine with the idea of providing value added inputs on the existing engine in terms of better Specific Fuel Consumption (SFC) and reduced pollutants.

Research work is in good progress and LHR engine is realized by Thermal Barrier Coating (TBC) of piston crown. Before coating on the actual piston, coating trials are in progress on aluminium plates, fabricated research pistons and tested for thermal barrier and thermal shock in in-house developed laboratory scale burner rig facility at the Surface Engineering Laboratory. Coatings also would be tested for adherence before implementing on the piston crown. Additional work involves development of simulation model and study of coating metrology to correlate the findings with any newer compositions that may be researched in the future.

About a dozen thrust areas are identified. Over half a dozen research faculties from various departments - Mechanical, Electrical, Electronics, Mathematics and Chemistry departments participate in this interdisciplinary research program along with thirty undergraduate research students. The potential includes: a) faculty pursuing Ph.D, b) Students performing research after prescribed academic hours and turning out project/fellowship reports and c) vendor development for associating with research work. While Amado Toolsand Spraymet industries in Bangalore are involved in fabrication of research components and plasma spraying activities respectively, the material characterization activities are supported by the Central Manufacturing Technology Institute (CMTI), Bangalore. The establishment and maintenance of diesel engine test rigs and laboratory burner rig is being managed by the involvement of Tech Ed Industries, Bangalore.

\section{INTRODUCTION}

In this paper, focus is on the applicability of TBCs on automotive components and therefore aluminium as the underlying metal.The technology and advantages of thermal barrier coatings (TBCs) on the hotter side of diesel or turbine engine components, although are well-established and accepted,the adaptability of these ceramics in different applications are still being pursued actively. Ceramic coatings are being considered for diesel engine cylinder liners, piston caps, valve faces and seats, piston rings, and other parts and for turbine components such as combustors, blades, stators, seals, and bearings.TBC's have been used to simulate adiabatic engines with the intention not only for reduced in-cylinder heat rejection and thermal fatigue protection of underlying metallic surfaces, but also for possible reduction of engine emissions[3 to 5].The operating efficiency of propulsion and power generation devices (such as diesel engines, gas turbines and jet engines) increases with their operating temperature [6].

The application of TBC's are expected to reduce the heat transfer to the engine cooling jacket through the combustion chamber surfaces (which include the cylinder head, liner and piston crown) and piston rings. The insulation of the combustion chamber with this coating, which is mainly ceramic based, influences the combustion process and hence the performance and exhaust emission characteristics of the engines. The former is easily understood from the first law of Thermodynamics, although the reduction in cylinder heat rejection may not favourably convert into a useful mechanical work but rather as an increased waste heat in the engine exhaust. The latter is extremely complicated because the increased air (or fuel-air mixture) temperature, due to the TBC (before the onset of combustion), could alter the ignition characteristic of the fuel-air mixture and its subsequent reaction mechanism, which are directly related to the exhaust emission characteristics. Moreover, the thermo physical properties of the coated ceramic and its surface roughness and pore characteristics (Number and Size), have a direct influence on un-burnt or partially burnt hydrocarbons through the surface quenching effect and their residence in the pores. 
The desire to increase thermal efficiency or reduce fuel consumption of engines makes it attractive to adopt higher compression ratios, in particular for diesel engines and reduced incylinder heat rejection. Both these factors lead to an increase in mechanical and thermal stresses. The durability concerns for the materials and components in the engine cylinders, which include piston, rings, liner and cylinder head, limit the allowable in-cylinder temperatures [7]. Application of TBC's to the surfaces of these components enhances high temperature durability by reducing the heat transfer and lowering temperatures of the underlying metal.Although 8YSZ is routinely applied as a TBC material, search is on for newer compositions that will offer improved coating configuration involving adhesion, thermal barrier and shock properties etc.

Many different kinds of ceramic materials and processes are being researched worldwide for finding a material and process configuration superior to the most popular TBC 8YSZ. By using pyrochlores $\left(\mathrm{A}_{2}{ }^{3+} \mathrm{B}_{2}{ }^{4+} \mathrm{O}_{7}\right.$ where $\mathrm{A}$ sites are Dy, La and $\mathrm{Sm}$ in place of $\left.\mathrm{Y}\right)$ or perovskites such as $\mathrm{SrZrO}_{3}$, reduced heat transfer and improvement in barrier properties have been observed by many researchers [8 to 13].However,involvement of the use of ceramic materials as TBC's has revealed widely differing aspects in practical applications[14].Partially/Fully Stabilized Zirconia (PSZ/FSZ)has excellent toughness, hot strength and thermal shock resistance, low thermal conductivity and a thermal expansion coefficient close to those of steel and cast iron. PSZ has been widely used as a TBC in the combustion of diesel engines [15, 16]. However, contradicting reports also do exist which questions the dominance of a TBC on an application.The applicability of TBC to Spark Ignition (SI) engine and Compression Ignition (CI) Engine is discussed in the paper bySivakumar and Shankar [17]. Hari [18] discusses the effect of TBC on eleven HP class engine. Kevin Vattappara[19] discussesyttria stabilized zirconia as TBC on metal substrates. Shankar et.al [20] have reported the results of their findings on the lab scale preparation and evaluation of yttria stabilized zirconia thermal barrier coatings and its influence on the diesel engine performance. Reghu [21] discusses TBC development on piston crown and simulation of LHR engines.

\section{Scope Of The Present Investigation}

The present investigation focuses on rectangular/square shapedaluminium substrates. TBCs with thickness between 200 microns and upto300 microns were prepared on 50-100 micron thick Nickel Aluminide ( $\mathrm{NiAl}$ ) bond coated aluminium substrates. Therefore the results presented here pertain to varying TBC thicknesses. The TBCs were prepared from $8 \% \mathrm{Y}_{2} \mathrm{O}_{3}-\mathrm{ZrO}_{2}$ plasma sprayable powders(prepared in the laboratory by using organic binders), coated onto $100 \mathrm{~mm} \mathrm{x}$ $100 \mathrm{~mm} \times 3 \mathrm{~mm}$ thickaluminium substrates, and subjected to thermal stress (thermal shock) cycles, evaluated for number of such heat-quench cycles they could withstand (or a predetermined number of stress cycles) before failure/visual degradation, and thermal barrier characteristics. Both the tests were carried out by using a Surface Engineering Laboratorydesigned and developed simulated burner rig facility. The as-sprayed and thermal tested specimens were subjected to Metrological studies.

The results obtained from the above tests were corroborated by a simulation model which involved the usage of parameters such as coating thickness, thermal conductivity, specific heat, and density as boundary conditions.

\subsection{Thermal Barrierand Thermal ShockTests}

The thermal barrier test involved exposing the ceramic coated surface with a high temperature flame focused on the centre of the coated specimen, allowing the ceramic surface sufficient time ( 2 hours) to attain the intended stabilized temperature under the steady flame conditions (flame temperatures $(\mathrm{T})$ varying from 250 upto $630^{\circ} \mathrm{C}$, (melting point of Aluminium: $660^{\circ} \mathrm{C}$ ) at regular 
$\Delta \mathrm{T}$ of $\sim 100$ degrees). The substrate temperature at the back of the specimen was measured to an accuracy of \pm 5 degrees.

The thermal shock test involved exposing the ceramic surface to $650^{\circ} \mathrm{C}$ for a pre-fixed amount of time (5 minutes) and suddenly withdrawing the specimen to face a blast of cold air to rapidly quench the hot ceramic surface including the aluminium substrate; thereafter reintroducing the ceramic surface to the flame after five minutes hold at the relatively colder ambient. The numbers of such heat quench cycles were recorded to assess the suitability of the TBC to protect the aluminium substrate from such an extremely harsh thermal environment. Figure. 1 shows the test facility along with a coated substrate.
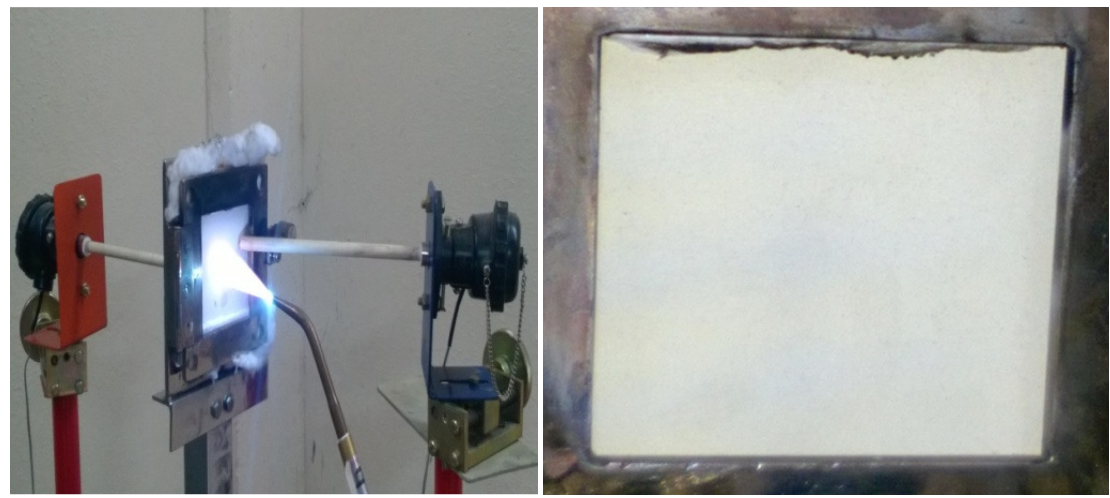

Figure 1. Simulated Burner Rig Test Facility at FECU with a typical Thermal Barrier Coated substrate mounted on test set-up.

\subsection{Metrological Studies on the TBCs}

The plasma sprayed aluminium plates, with as-sprayed coatings and after undergoing thermal stress tests were subjected to the following metrological tests.

- Structural phase analysis

- Microstructure analysis on metallographic cross section specimen

3.2.1. Structural phase analysis: the structural phase analysis was carried out on the ceramic surface by employing the X-ray Diffractometer (XRD). The TBC surface was scanned between $2 \theta$ values of 20 and 100 degrees.

3.2.2.Determination of $\mathbf{c} / \mathbf{t}-\mathrm{ZrO}_{2}$ phase: The percentage of stabilization of the cubic/tetragonal $(\mathrm{c} / \mathrm{t})$ and monoclinic $(\mathrm{m})$ zirconia was determined from the $\{111\}$ family of planes by using the following equation:

$$
\begin{aligned}
& \% \mathrm{~m}-\mathrm{ZrO}_{2}=\underline{\mathrm{I}}_{\underline{\mathrm{m}(111)}}+\mathrm{I}_{\underline{\mathrm{m}(11 \overline{1})}} \\
& \mathrm{I}_{\mathrm{m}(11 \overline{\mathbf{1}})}+\mathrm{I}_{\mathrm{m}(111)}+\mathrm{I}_{\mathrm{t}(111)} \\
& \% \mathrm{c} / \mathrm{tZrO}_{2}=1-\% \mathrm{~m}-\mathrm{ZrO}_{2}
\end{aligned}
$$

Where, $\mathrm{m}=$ monoclinic, $\mathrm{t}=$ tetragonal, $\mathrm{I}=$ intensity 
3.2.2. Microscopy:The coating stability before (as -sprayed) and after the thermal stress test was determined by visually studying the adhesion of the (i) ceramic with the bond coat and the (ii) substrate with bond coat as well. The study was conducted on the metallographic cross section of the plates ina Scanning Electron Microscope (SEM). Cracks generated during the thermal stress testing, formation of any defects including cohesive/adhesive failure, delamination, macro defects etc. also were addressed in this analysis. The TBC surface also was examined.

\subsection{Simulation Model Involving TBCs}

The prime role of a TBC is to introduce a temperature drop across the thickness of the coating by the merit of the thermal insulation characteristics it possesses. In addition to the thermal conductivity, the other contributing characteristics are : (a) Coating Thickness, (b) Coating Surface Temperature, (c) Coating and Substrate Specific Heat, (d) Density and finally (e) the Ambient Environment Conditions.

These parameters have been used to simulate a model in order to be able to predict the ability of the 8YSZ coatings to function as TBC's as well as their efficiency in terms of temperature drop across the coating.

The model of the TBC coated substrate was prepared by using the Solid Edge V18 platform. Then the model was imported into Hypermesh 13.0 and meshed with each zone being done separately. The meshed model was then imported to Ansys Fluent 14.5, where the model was given its material properties and it was simulated for different temperatures (varying from $250^{\circ} \mathrm{C}$ up to $650^{\circ} \mathrm{C}$, at regular $\Delta \mathrm{T}$ of $\sim 100$ degrees). A suitable ambient temperature higher than room temperature was incorporated in the model which varied with each rise in temperature.

\section{SALIENT FINDINGS}

\section{1: Thermal Barrier and Thermal Shock tests}

4.1.1: Thermal Barrier Test:Fig.2 shows the test results of the thermal barrier tests described in section 3.1 and Fig.1.

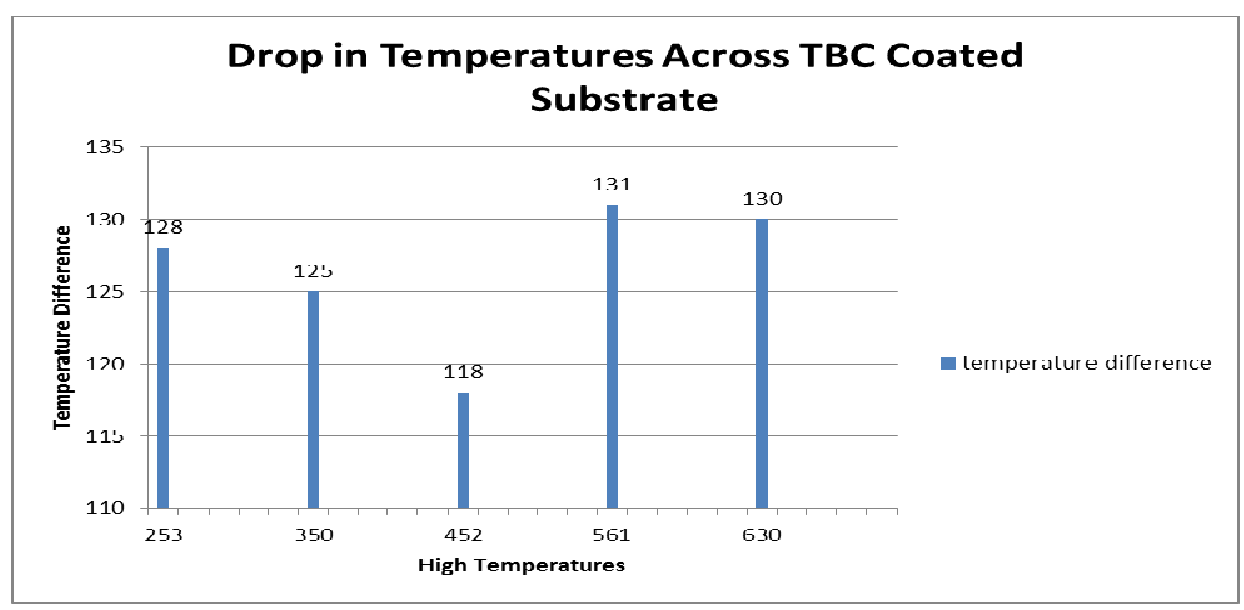


Figure 2. Thermal barrier test results -Temperature drop across the TBC with the Ceramic Surface at the High temperature shown in the $\mathrm{X}$-Axis (C)

\subsection{2: Thermal Shock Test}

The TBC, described in the previous section was subjected to more than 500 heat - quench cycles before the test was stopped. At the end of 500 cycles with the ceramic surface temperature maintained at $630^{\circ} \mathrm{C}$, visual inspection of the TBC showedrevealed no degradation or cracking of the top coat and no detachment from the substrate.

In order to provide a very harsh test condition, and to explore if higher flame temperature at the ceramic surface would provide the much needed thermal stress to delaminate the coating from the substrate, the flame temperature was increased to about $800^{\circ} \mathrm{C}$ for a brief period of 3 minutes. With an anticipated temperature drop of $\sim 130^{\circ} \mathrm{C}$, the metal substrate was expected to briefly experience a temperature of $\sim 670^{\circ} \mathrm{C}\left(800-130^{\circ} \mathrm{C}=670^{\circ} \mathrm{C}\right)$, higher than the melting temperature of aluminium $\left(660^{\circ} \mathrm{C}\right)$ and thus the onset of melting would occur.Yet, at the end of this experiment, no spalling of the coating was observed. This sample was studied further for structural phase change and microstructure.

\subsection{Metrological Studies on the TBCs}

4.2.1 Structural phase analysis: Figure 3 shows the XRD pattern of (a) surface of the assprayed coating and (b) the surface after subjected to 500 thermal stress cycles between $650^{\circ} \mathrm{C}$ and ambient.

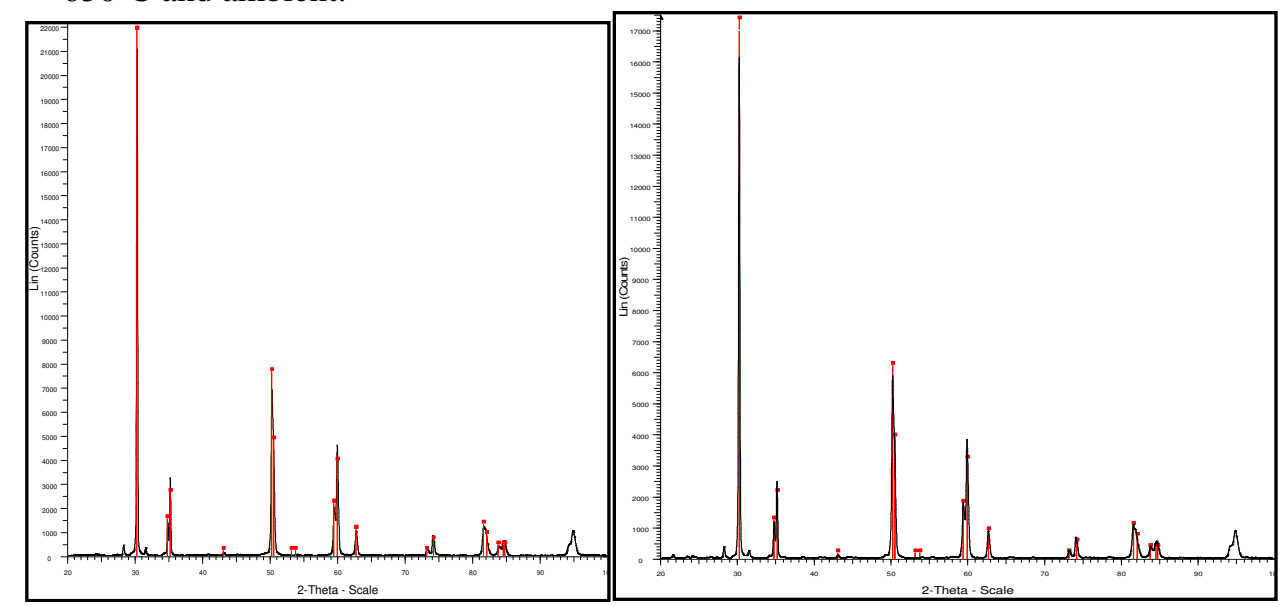

(a) XRD pattern of as sprayed TBC (b)XRD pattern of TBC after thermal stress test

(500 heat quench cycles between $650^{\circ} \mathrm{C}$ and ambient)

Figure 3. XRD Patterns ( $2 \theta$ between 20 and 100 degrees)

XRD patterns shown above exhibit the presence of two zirconia phases:cubic /tetragonal (c/t) and monoclinic (m) zirconia. The $100 \% \mathrm{c} / \mathrm{t}-\mathrm{ZrO}_{2}$ is reflected at the $2 \theta=30$ degrees peak in the pattern. The two peaks adjacent to the major $\mathrm{c} / \mathrm{t}-\mathrm{ZrO}_{2}$ peak belong to the $\mathrm{m}-\mathrm{ZrO}_{2}$. All the three peaks around $2 \theta=30$ degrees, belong to the $\{111\}$ family of planes of $\mathrm{ZrO}_{2}$. The desired phase of TBC application is c/t- $\mathrm{ZrO}_{2}$.

Presence of $\sim 87 \%$ of $\mathrm{c} / \mathrm{t}-\mathrm{ZrO}_{2}$ calculated from the XRD pattern shown in Figure 3(a) confirmed the stabilization of the desired phase in as-sprayedYSZ TBC. As expected ,the thermal shock cycling test did not introduce any significant de-stabilization effects as evident from the XRD 
pattern shown in Figure 3(b). This is because; temperature in the vicinity of $700^{\circ} \mathrm{C}$ was not high enough to destabilize the c/t- $\mathrm{ZrO}_{2}$ phase during the experiment. The calculations revealed $\% \mathrm{c} / \mathrm{t}$ $\mathrm{ZrO}_{2}$ in pattern after thermal stress cycling to be $\sim 85 \%$.

\subsubsection{Microstructure analysis on cross sectional metallographic specimen}

Figure 4 shows the as-sprayed TBC in a metallographic polished cross-section.

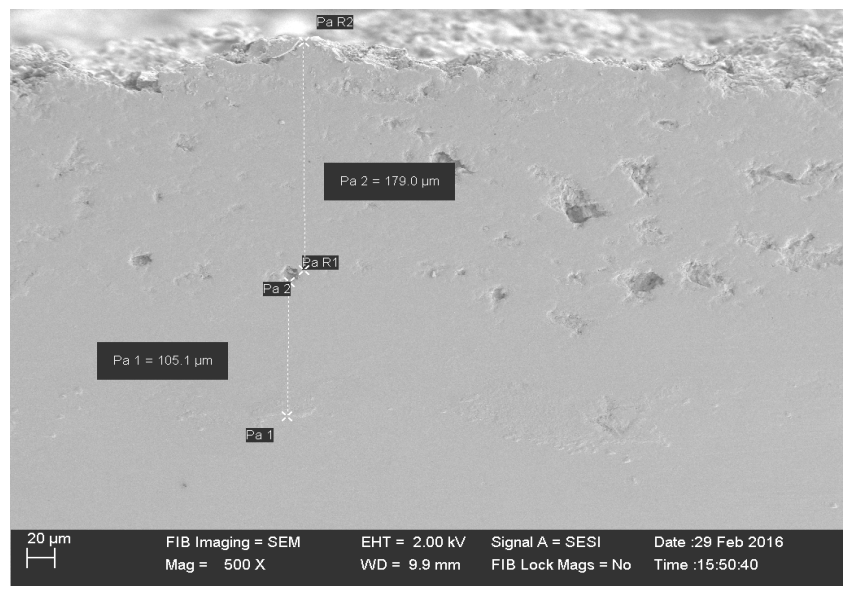

Figure 4. SEM micrograph for the as-sprayed sample

Detailed metallographic cross-section analysis of the as-sprayed TBC revealed a smooth and defect free ceramic bond coat and bond coat substrate interface. The coating thickness varied between 180 and 210 microns with an average thickness of about 200 microns on 100 microns (average) NiAl bond coat. The defects seen in ceramic top coat are attributed to grain pull-out during the process of grinding and polishing.

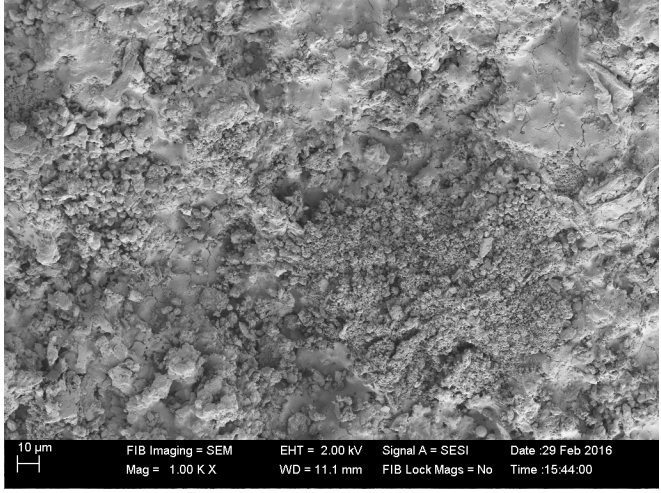

(a)

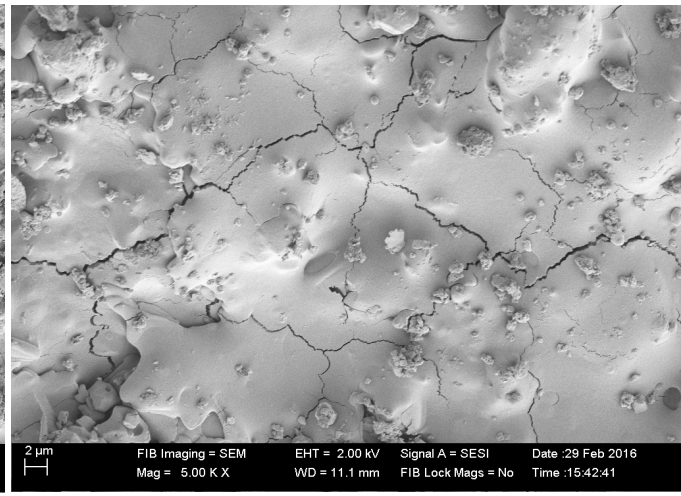

(b)

Figure 5.SEM micrograph of TBC as sprayed surface at (a) 1000X and (b) 5000X.

The as-sprayed surface shown in Figure 5 ( $a$ and $b$ ), exhibited several micro-cracks generated typically during the process of plasma spraying as consequence of stresses generated within the ceramic during rapid cooling.

Surprisingly, cross section metallography of the thermal stress cycled specimen shown in Figure 6.revealed a microstructure no different from the as-sprayed specimen. Smooth defect free 
topcoat-bondcoat and bond coat-aluminum substrate interface showed minimum to least amount of oxidation of the metals/bond coat alloy. Although aluminium melts at $660^{\circ} \mathrm{C}$, there were no signs of any melting or deformation when the TBCs on aluminum were exposed to the high flame temperature of $630^{\circ} \mathrm{C}$. Even then the aluminium substrate has not undergone any deformation.

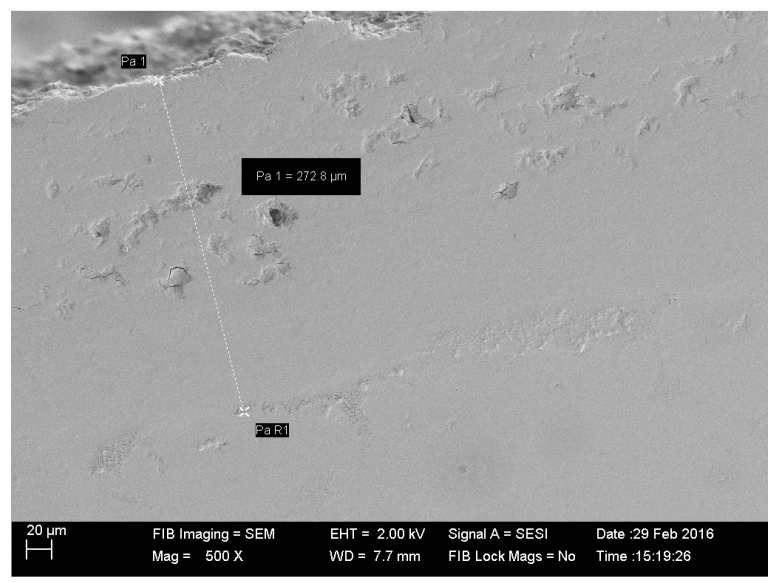

Figure 6. SEM micrograph of TBC on thermally stressed surface.

Thermal barrier tests have shown a maximum temperature drop of about $130^{\circ} \mathrm{C}$ across the $\mathrm{TBC}$. Thus it is expected that the temperature experienced by the underlying metal substrate has not crossed about $500^{\circ} \mathrm{C}$ during the planned thermal shock cycling testing. The specimen has been exposed to a flame at $650^{\circ} \mathrm{C}$ for nearly 40 hours .

In addition, the ceramic surface was also exposed to $800^{\circ} \mathrm{C}$ briefly for about 3 minutes, which means the underlying metal was exposed to a temperature of about $670^{\circ} \mathrm{C}$, which is beyond the melting temperature of aluminium.Closer examination of the bond coat-substrate interface revealed isolated pockets of crack network. This is attributed to the flexing of the metal substrates in some position to the extreme (induced) thermal stress it has undergone and yet the coating did not peel off the substrate. A typical micrograph is shown in Figure 7.

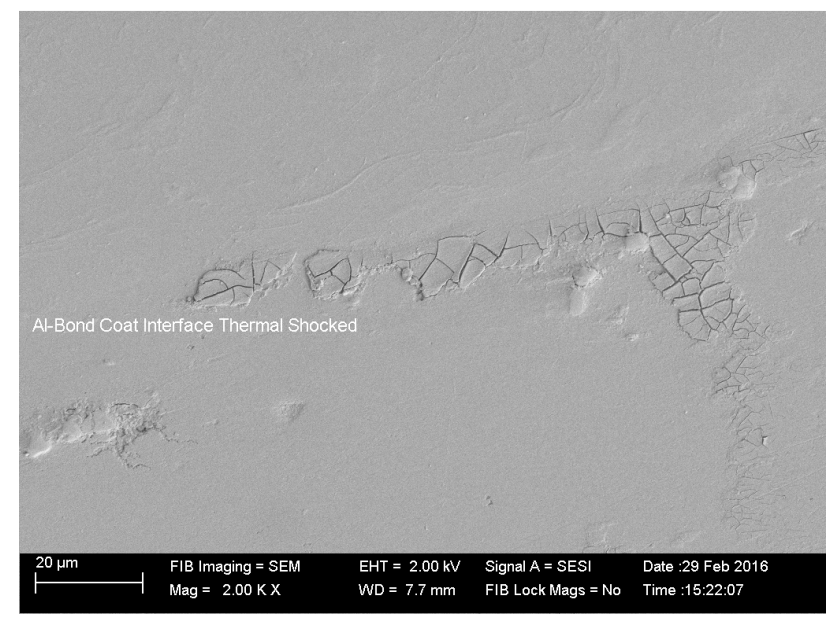

Figure 7. SEM cross section micrograph of TBC on thermally stressed surface revealing cracks the aluminium-bond coat interface.

This experiment confirms the soundness of the TBCs and the coating configuration. 


\section{3: Simulation Model Involving TBCs}

A simulation model was developed to corroborate the results of the thermal stress tests. Generally the most commonly used TBCs are about 300 micron thick with bond coats of 50 micron thickness. Therefore, the model developed pertains to such a coating configuration. In the future, it is planned to further build the models and predict the results of newer TBC configurations with compositions other than 8 YSZ.

\subsubsection{Simulation Model Development}

Figure 8.shows a snapshot of a part of the model developed for the TBC on aluminium substrate with 300 micron thick coating on 50 micron thick Nickel Aluminide (NiAl) bond coat including an area of Air Domain using Solid Edge V18® simulation software.

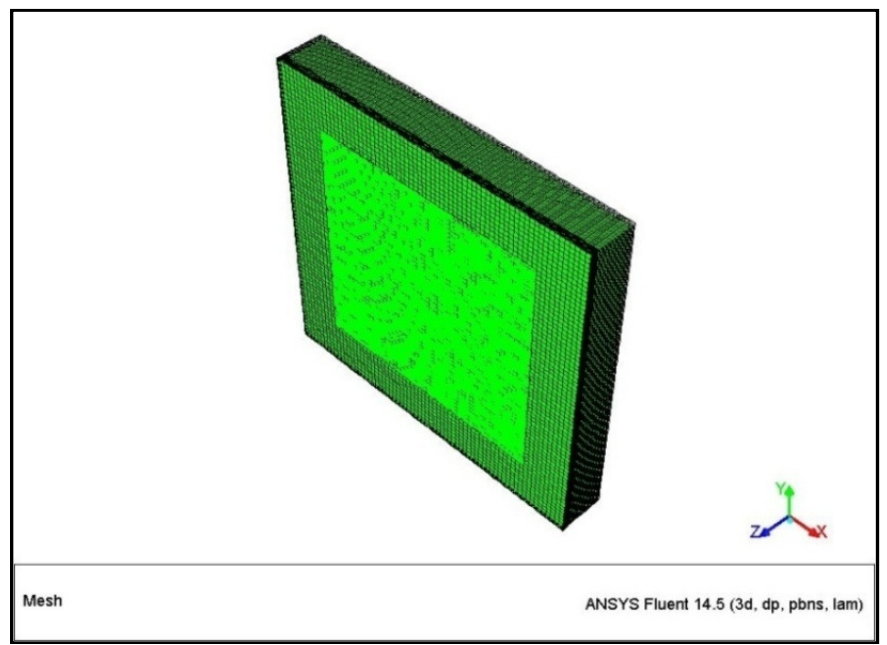

Figure 8: Snapshot of a part of the model developed

4.3.2Figure 9. (a through e) shows the temperature contours showing the $\Delta \mathrm{T}$ across the thickness of the TBC, bond coat and substrate.

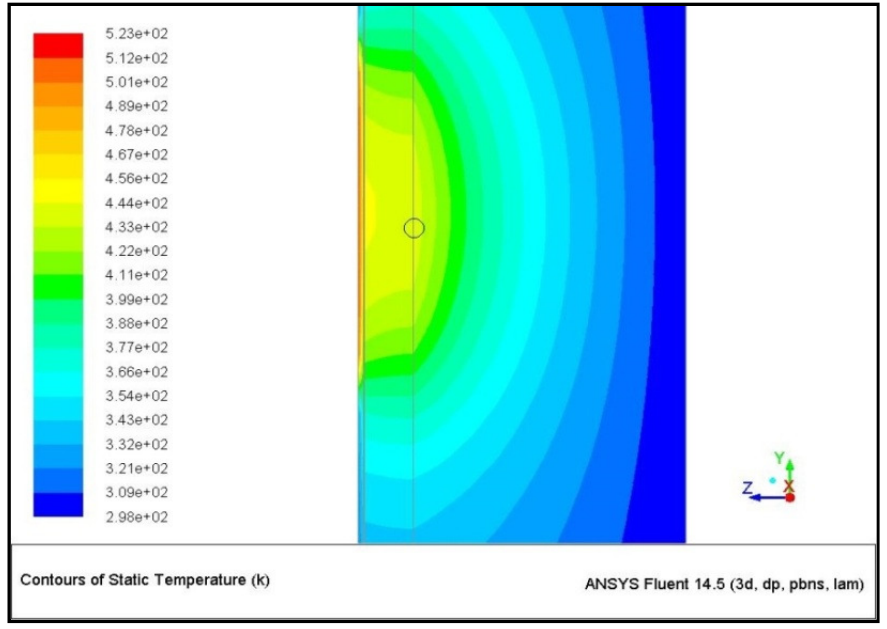

(a) Temperature Contour for $250^{\circ} \mathrm{C}(523 \mathrm{~K})$ 
Advances in Materials Science and Engineering: An International Journal (MSEJ), Vol. 3, No. 2, June 2016

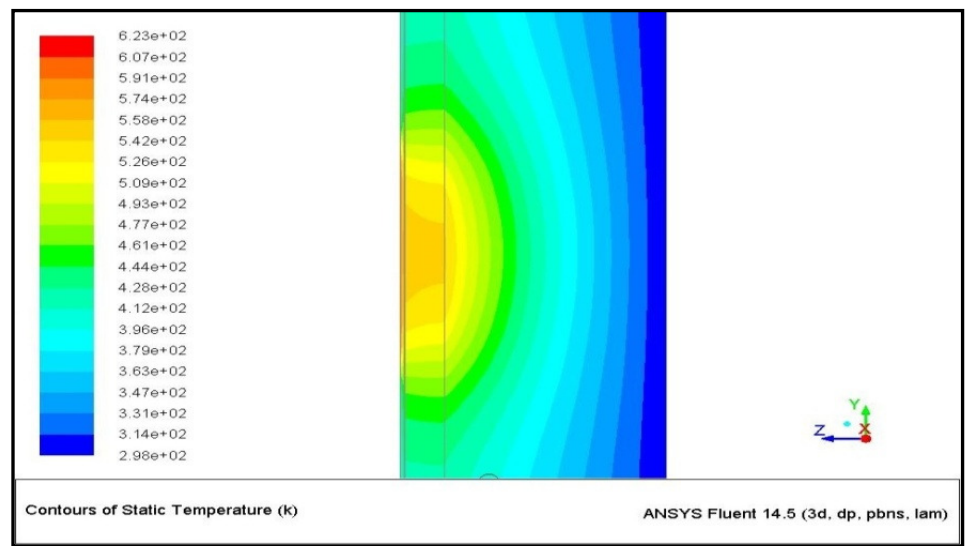

(b) Temperature Contour for $350^{\circ} \mathrm{C}(623 \mathrm{~K})$

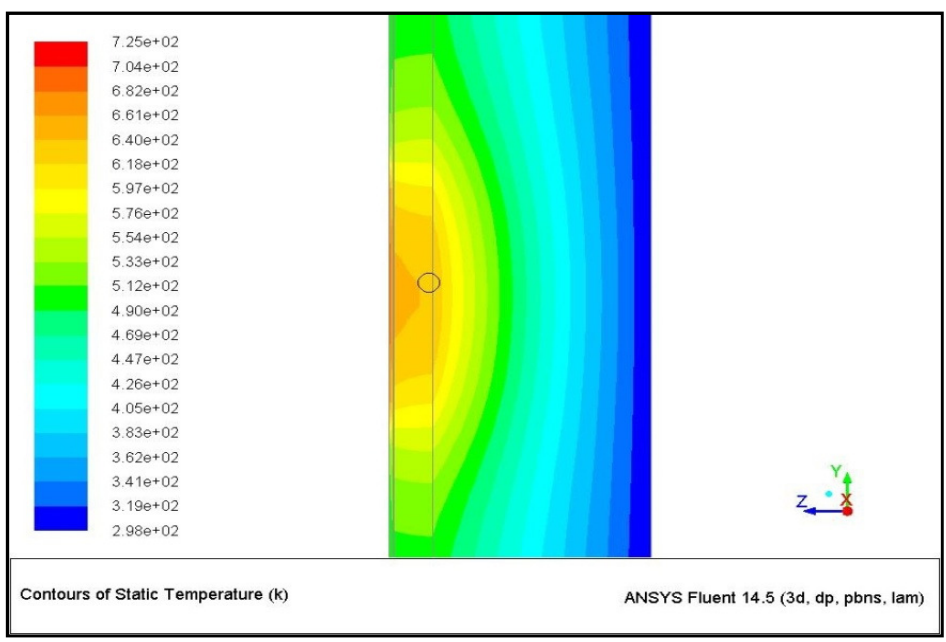

(c) Temperature Contour for $450^{\circ} \mathrm{C}(723 \mathrm{~K})$

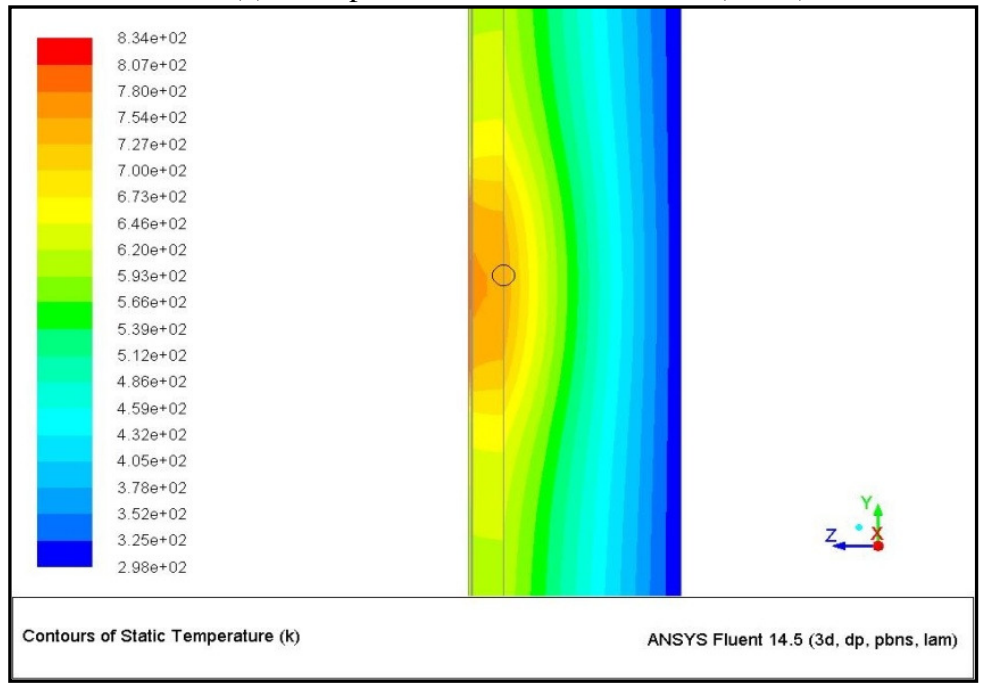

(d) Temperature Contour for $550^{\circ} \mathrm{C}(823 \mathrm{~K})$ 


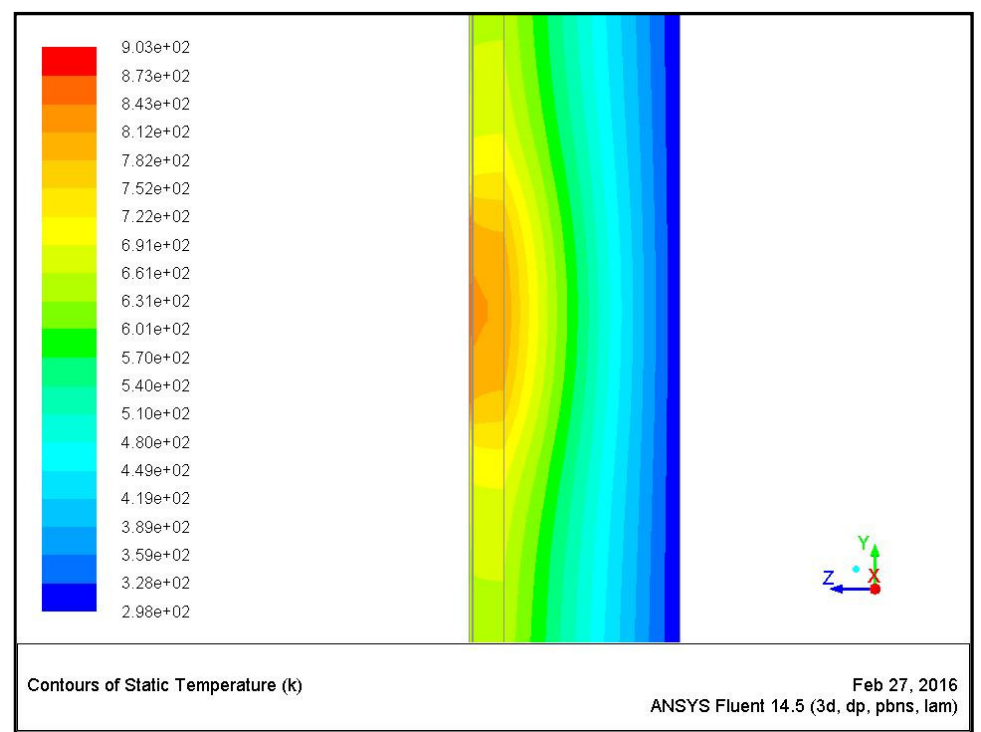

(e) Temperature Contour for $630^{\circ} \mathrm{C}(903 \mathrm{~K})$

Figure 9. (a through e): Temperature Contours showing the $\Delta \mathrm{T}$ across the thickness of the TBC, bond coat and the substrate.

The temperature contours shown in temperature scale (depicted in Kelvin Scale) in each Figure of 9 (a through e ) signify the range of temperature (room temperature to the maximum attained for the particular experiment) under investigation. The maximum temperature set for these experiments were $250^{\circ} \mathrm{C}$ (Figure $9 \mathrm{a}$ ), $350^{\circ} \mathrm{C}$ (Figure 9b), $450^{\circ} \mathrm{C}$ (Figure $9 \mathrm{c}$ ), $550^{\circ} \mathrm{C}$ (Figure $9 \mathrm{~d}$ ) and $630^{\circ} \mathrm{C}$ (Figure $9 \mathrm{e}$ ).

The temperature drop across the thickness of the coatings ( 350 microns), substrate $(3.0 \mathrm{~mm})$ and air domain $(\sim 20.0 \mathrm{~mm})$ in each temperature contour is shown separately in the above figures (Figure 9. (a through e)). The same results are depicted in graphical form in the following figures.

\subsubsection{Contour Plots}

Figure 10. (a through e) shows the graphs pertaining to the temperature contours of the $\Delta \mathrm{T}$ across the thickness of the TBC, bond coat and substrate, shown in Figure 9. (a through e).

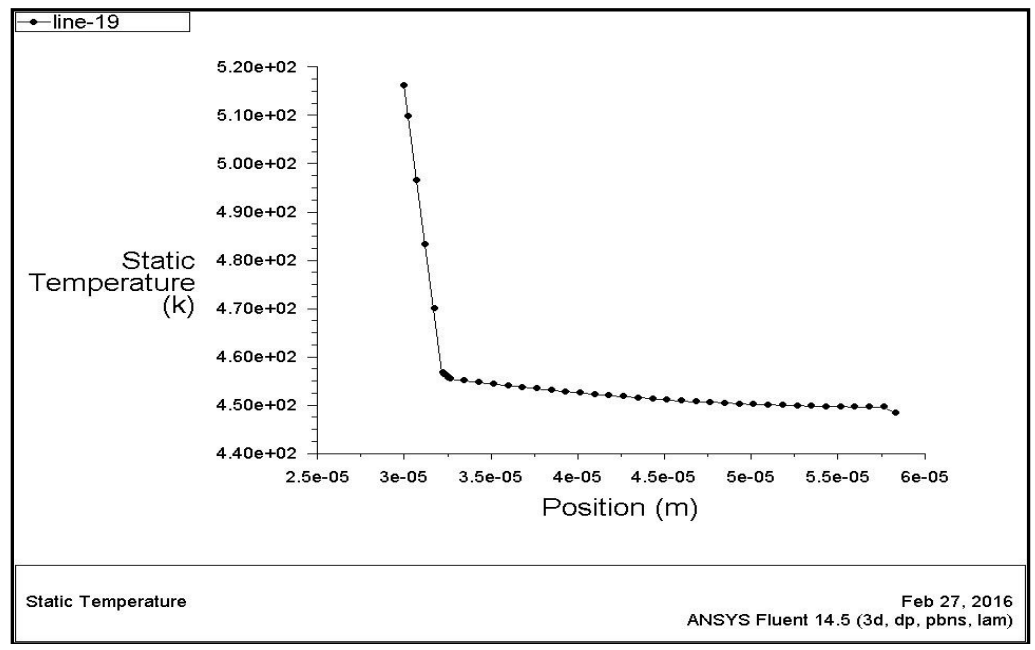

(a) Graph for $250^{\circ} \mathrm{C}(523 \mathrm{~K})$ 


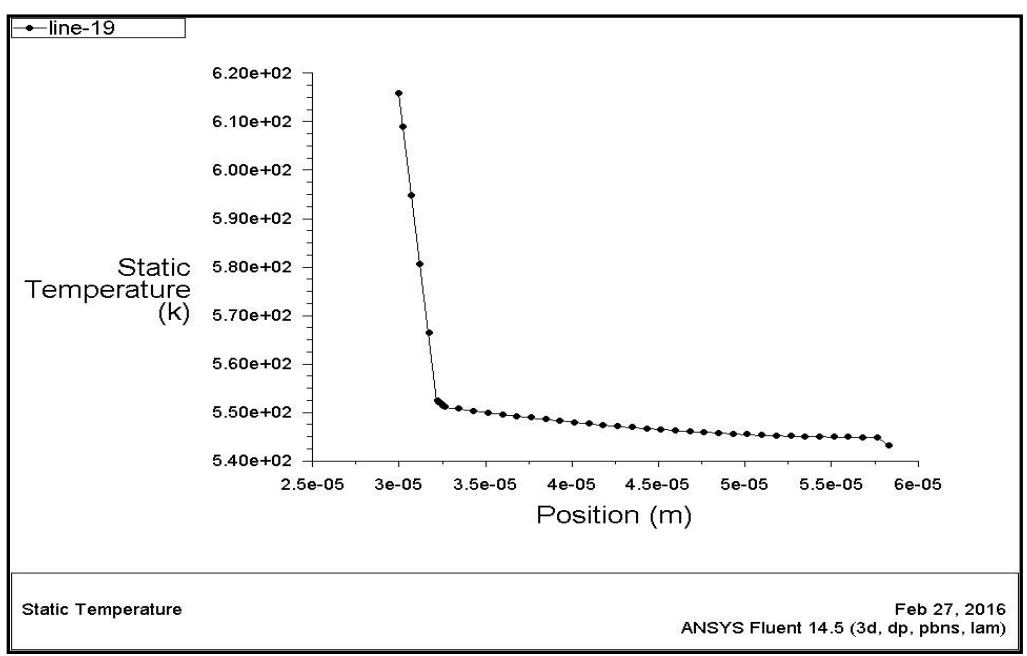

(b) Graph for $350^{\circ} \mathrm{C}(623 \mathrm{~K})$

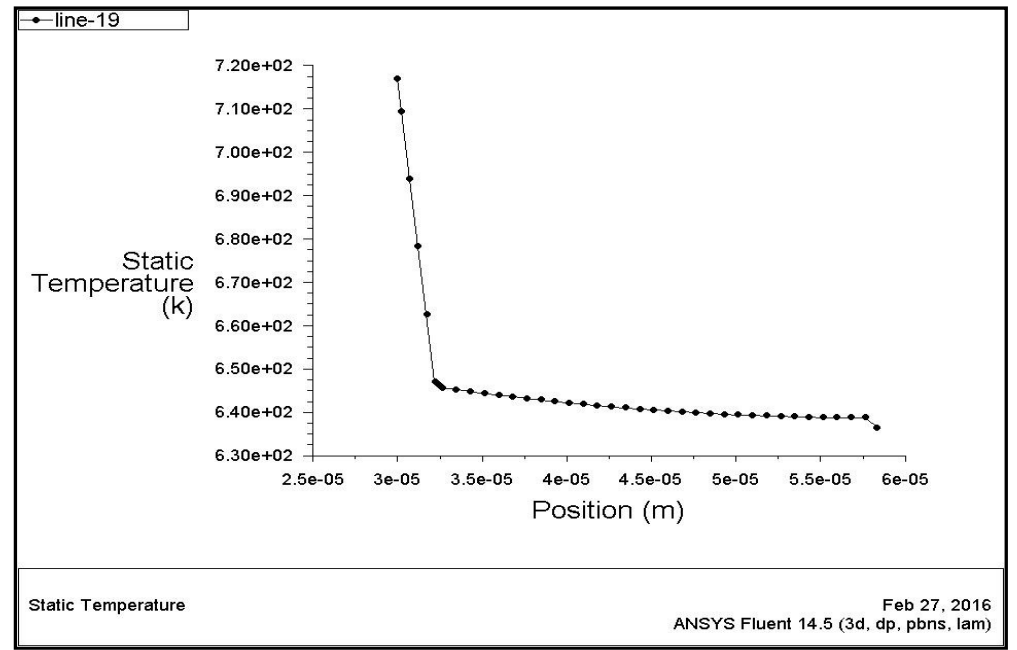

(c) Graph for $450^{\circ} \mathrm{C}(723 \mathrm{~K})$

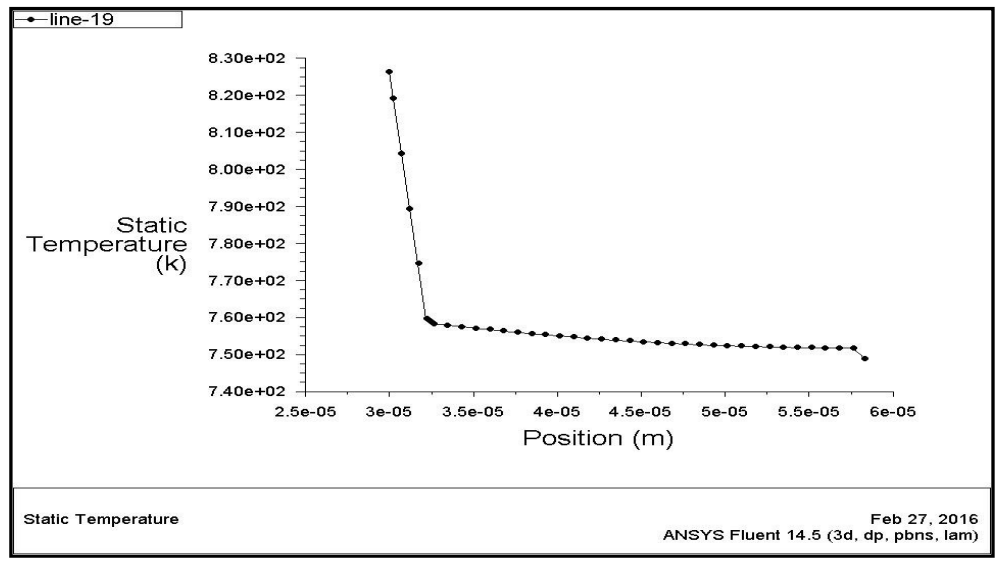

(d) Graph for $550^{\circ} \mathrm{C}(823 \mathrm{~K})$ 


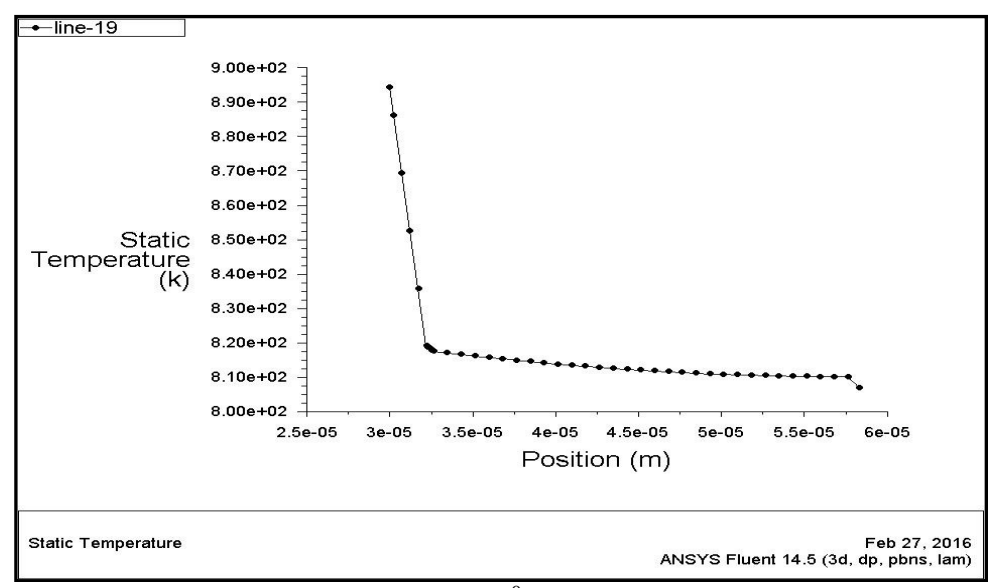

(e) Graph for $630^{\circ} \mathrm{C}(903 \mathrm{~K})$

Figure 10. (a through e): Graphs pertaining to temperature contours showing the $\Delta \mathrm{T}$ across the thickness of the TBC, bond coat and substrate.

\subsection{Summary of Experimental Results}

Thermal barrier coatings (TBCs) from laboratory processed plasma sprayable powders from $8 \mathrm{Y}_{2} \mathrm{O}_{3}$-stabilized zirconia were prepared on rectangular aluminum plates. The plates were subjected to thermal stress and barrier tests and the severly heat affected plates were evlauated for structural phase and microstructural degradation. None were found and the results confirmed that the coatings were of good quality.

In order to predict the potential of new compositions that would be devloped in the laboratory for possible TBC applications in the future, a simulation model was developed by incorporating the results obtained in this work.

\section{CONCLUSION}

In this paper, results of thermal stress tests on aluminum plates coated with 8YSZ TBCs are presented along with temperature contours simulation models after corroboration with the test results.The coatings have exhibited no degradation when tested with burner rig flame surface temperature as high as $630^{\circ} \mathrm{C}$ thereby indicating that the aluminium plate was in principle exposed to a flame close to its melting temperature for nearly 40 hours without showing any signs of failure. This is because the aluminium plate was actually experiencing a temperature of only $500^{\circ} \mathrm{C}$ because of the thermal barrier effects provided by the 8 YSZ TBC. The simulation models are expected to provide a framework for exploring the potential of TBCs with newer compositions prior to actually beginning the TBC preparation process in the practically rigorous way.

Work is in progress towards coating trials on specially fabricated research piston to finalize the optimum coating parameters and implement LHR concept in four cylinder engine. Adequate number of thermal barrier and thermal shock tests would be carried out on research pistons,prior to the implementation of LHR concept in four cylinder engine.

\section{ACKNOWLEDGEMENT}

Authors would like to acknowledge with thanks the Christ University Management headed by Vice Chancellor, Dr. (Fr.) Thomas C Mathew, Engineering Director Fr. Benny Thomas, Associate Director (Centre for Research-Projects) Prof. D.N.S Kumar, Associate Dean, Faculty of Engineering Dr. Iven Jose and Mechanical Department Co-Ordinator Dr. Gurumoorthy 
Advances in Materials Science and Engineering: An International Journal (MSEJ), Vol. 3, No. 2, June 2016

Hebbar for encouraging R \& D work.Discussions with Dr. Ganesan V., (Retired Professor, IIT Madras) and presently visiting faculty at Christ University are acknowledged.Authors would like to acknowledge with thanks the work on conjugate heat transfer by Mechanical Engineering Department, Assistant Professor and Research Faculty Mr. Thejaraju.

\section{REFERENCES}

1. Shankar. V, Experimental Studies on Seventy Two Horse Power Class Four Cylinder Diesel Engine, Research Proposal, Report no. CUFE/MRP/001/2013,Christ University, Sep 2013.

2. D.N.S Kumar, Approval of Major Research Proposal on Experimental Studies on Seventy Two HP Class Four Cylinder Diesel Engine, Nov 2013.

3. IlkerTurgutYilmaz, MetinGumus, Mehmet Akçay, "Thermal Barrier Coatings for Diesel Engines.," International Scientific Conference, Vol.2. pp. 173-177,November2010.

4. G. Sivakumar, S. Senthil Kumar, "Investigation on effect of Yttria Stabilized Zirconia coated Piston crown on performance and emission characteristics of a Diesel Engine.," Alexandria Engineering Journal,Vol.54., pp. 787-794, August 2014.

5. T.M. Yonushonis, "Overview of Thermal Barrier Coatings in Diesel Engines,"IEEEJournal of Thermal Spray Technology.Vol.6, pp. 50-56, July 1997.

6. David R. Clarke, Matthias Oechsner, Nitin P. Padture, "Thermal-barrier coatings for more efficient gas-turbine engines."Materials Research Society Bulletin No.10, Vol. 37, pp. 891-898, October 2012.

7. P. Arjunraj, Dr. M. Subramanian, N. RathinaPrakash, "Analysis and Comparison of Steel Piston over Aluminium Alloy Piston in Four Stroke Multi-cylinder Diesel Engine.”International Journal of Emerging Technologyand Advanced Engineering, Vol. 5, pp. 116-122, ISSN: 2250-2459, December 2015.

8. B Saruhan, P Francois, K Fritscher, U Schulz, "EB-PVD processing of pyrochlore-structured La2Zr2O7-based TBCs", Surface and Coatings Technology, Vol. 182, pp. 175-183, Issues 2-3, 22 April 2004.

9. Narottam P. Bansal, Dongming Zhu, Maryam Eslamloo-Grami, "Effects of Doping on Thermal Conductivity of Pyrochlore Oxides for Advanced Thermal Barrier Coatings" NASA/TM-2006214483, December 2006.

10. W. Ma, M.O. Jarligo, D.E. Mack, D. Pitzer, J. Malzbender, R. Vaßen, and D. Stover, "New Generation Perovskite Thermal Barrier Coating Materials" Journal of Thermal Spray Technology, volume 17(5-6), pp.831-837, Mid-December 2008.

11. Giovanni Di Girolamo, CaterinaBlasi, AlidaBrentari, Monica Schioppa, "Microstructure and thermal properties of plasma-sprayed ceramic thermal barrier coatings, EAI Energia, Ambiente e Innovazione, pp. $69-76,1-2 / 2013$.

12. G. Mauer, N. Schlegel, A. Guignard, M.O. Jarligo, S. Rezanka, A. Hospach, R. Vaßen, "Plasma Spraying of Ceramics with Particular Difficulties in Processing" Thermal Spray 2014: Proceedings of the International Thermal Spray Conference, pp. 397 - 402, Barcelona, Spain, May 21-23 2014.

13. T. Sadowski and P. Golewski, "Protective Thermal Barrier Coatings, Loadings in Thermal Barrier Coatings of Jet Engine Turbine Blades, Springer Briefs in Computational Mechanics, DOI 10.1007/978-981-10-0919-8_2, 2016, pp. 5-11.

14. M.Azadi, M. Baloo et.al., " A Review of Thermal Barrier Coating Effects on Diesel Engine Performance and Component Life time" International Journal of Automotive Engineering, Vol.3, pp 305-317, No. 1, March 2013.

15. X.Q. Cao, R. Vassen, and D. Stover, "Ceramic materials for thermal barrier coatings”, Journal of European Ceramic Society,Vol. 24, pp.1-10, 2004.

16. Chan S., H. and Khor K., A. "The effect of thermal barrier coated piston crown on engine characteristics", Journal of Materials Engineering and Performance, Vol.9(1), pp.103-109, 2000.

17. G. Sivakumar, V. Shankar et. al, "Is Thermal Barrier Coating for Low Heat Rejection in SI or Diesel Engines", International Journal of Emerging Technologies and Advanced Engineering, Vol. 2, Issue 12, Dec 2012. 
18. Hari et.al, "Experimental Studies on Performance Improvements of Eleven HP Class Diesel Engine with Ceramic Coating", B Tech Project Report, Vel Dr. RR \& SR Technical University, Chennai, March 2013.

19. Kevin Vattappara, "Studies on Yttria Stabilized Zirconia as Thermal Barrier Coatings on Metal Substrates", B Tech Project Report, Christ University, Bangalore March 2016.

20. Shankar. V, V.R. Reghu, ParvatiRamaswamy and Kevin Vattappara, "Lab Scale Preparation and Evaluation of Yttria Stabilized Zirconia Thermal Barrier Coatings and Its Influence on the Diesel Engine Performance", presented at the RTME, Dubai, April 23-24, 2016, Accepted for publication in the International Journal of Recent advances in Mechanical Engineering (IJMECH) Vol.5, pp. 1-19, No.2, May 2016.

21. V. R. Reghu, "Thermal Barrier Coating Development on Piston Crown and Simulation of Low Heat Rejection Engine”, Ph.D. Scholar,Dissertation in Progress, Christ University, Bangalore. 